\title{
Microstructure and stress rupture properties of polycrystal and directionally solidified castings of nickel-based superalloys
}

\author{
Bao-ping $W u^{1,2)}$, Lin-han $\mathrm{Li}^{2}$, Jian-tao Wu ${ }^{1)}$, Zhen Wang ${ }^{1)}$, Yan-bin Wang ${ }^{1)}$, Xing-fu Chen ${ }^{1)}$, \\ Jian-xin Dong ${ }^{2}$, and Jun-tao Li ${ }^{1}$ \\ 1) Central Iron \& Steel Material Research Institute, Beijing 100081, China \\ 2) School of Materials Science and Engineering, University of Science and Technology Beijing, Beijing 100083, China \\ (Received: 13 June 2013; revised: 7 August 2013; accepted: 15 August 2013)
}

\begin{abstract}
A new directionally solidified Ni-based superalloy DZ24, which is a modification of K24 alloy without rare and expensive elemental additions, such as Ta and Hf, was studied in this paper. The microstructure and stress rupture properties of conventionally cast and directionally solidified superalloys were comparatively analyzed. It is indicated that the microstructure of K24 alloy is composed of $\gamma, \gamma^{\prime}, \gamma / \gamma^{\prime}$ eutectics and MC carbides. Compared with the microstructure of K24 polycrystalline alloy, $\gamma / \gamma^{\prime}$ eutectic completely dissolves into the $\gamma$ matrix, the fine and regular $\gamma^{\prime}$ phase reprecipitates, and $\mathrm{MC}$ carbides decompose to $\mathrm{M}_{6} \mathrm{C} / \mathrm{M}_{23} \mathrm{C}_{6}$ carbides after heat treatment in DZ24 alloy. The rupture life of DZ24 alloy is two times longer than that of K24 alloy. The more homogeneous the size of $\gamma^{\prime}$ precipitate, the longer the rupture life. The coarsening and rafting behaviors of $\gamma^{\prime}$ precipitates are observed in DZ24 alloy after the stress-rupture test.
\end{abstract}

Keywords: superalloys; nickel alloys; microstructure; precipitation; carbides; mechanical properties

\section{Introduction}

K24 superalloy is one of the most excellent conventional cast superalloys that can tolerate average temperature from 900 to $1000^{\circ} \mathrm{C}$. It is widely used in aircraft and power-generation turbines, rocket engines, and other challenging environments as equiaxed polycrystal materials. However, equiaxed grain boundaries of K24 superalloy are the sites for damage accumulation at high temperature; crack growth will suddenly occur in the use of early stages. To solve this problem, the directional solidification process is applied for producing columnar-grained blades with a directional structure (without grain boundaries perpendicular to the blade axis).

The cost of directionally solidified casting is substantially lower than that of single crystal casting. This is because the directional solidification process is faster, the yield is higher, and the inspection cost is considerably lower [1-2]. Directionally solidified castings possess only a few columnar grains, which are oriented in the $<100>$ crystallographic direction. The stress-rupture life of directionally solidified castings is much higher than that of polycrystal castings, which accounts for the absence of transverse grain boundaries in directionally solidified castings.

In this paper, the microstructure of new directionally solidified Ni-based superalloy DZ24 by modification of K24 and its rupture properties were discussed, comparing with those of polycrystal K24 superalloy.

\section{Experimental}

The conventionally and the directionally solidified superalloy specimens (13 $\mathrm{mm}$ in diameter) were produced by vacuum precision casting. The grain size of the conventionally cast specimen is about $2 \mathrm{~mm}$ and uniform, as shown in Fig. 1(a). DZ24 specimens were cast with a withdrawal rate of $6 \mathrm{~mm} / \mathrm{min}$ in a Bridgeman type furnace. The macrostructure of a longitudinal section of the directionally solidified casting (Fig. 1(b)) shows a short chill zone of fine grains having a random orientation and an extended columnar zone of grains growing normal to the copper chill plate and in the direction of temperature gradient. The compositions of K24 and DZ24 alloys are shown in Table 1. 

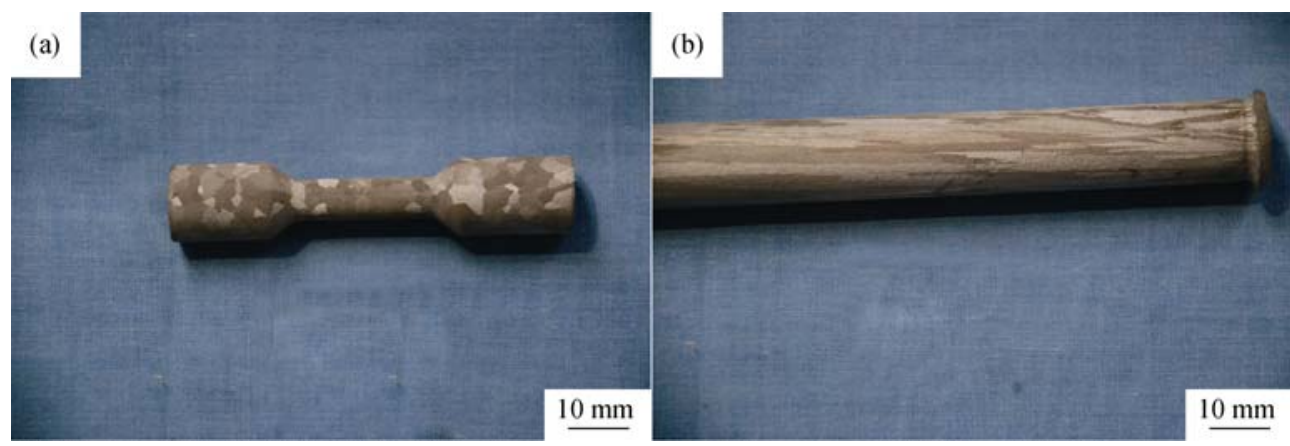

Fig. 1. Macrostructures of K24 (a) and DZ24 (b) alloys.

Table 1. Chemical compositions of the tested alloys

wt\%

\begin{tabular}{cccccccccccccc}
\hline Alloy & $\mathrm{C}$ & $\mathrm{Cr}$ & $\mathrm{Co}$ & $\mathrm{W}$ & $\mathrm{Mo}$ & $\mathrm{Al}$ & $\mathrm{Ti}$ & $\mathrm{V}$ & $\mathrm{Nb}$ & $\mathrm{B}$ & $\mathrm{Zr}$ & $\mathrm{Ni}$ \\
\hline K24 & 0.17 & 9.88 & 13.33 & 1.43 & 3.13 & 5.43 & 4.46 & 0.88 & 0.78 & 0.0061 & 0.011 & $\mathrm{Bal}$. \\
DZ24 & 0.16 & 9.33 & 13.92 & 1.41 & 3.25 & 5.42 & 4.57 & 0.84 & 0.83 & 0.0063 & 0.013 & $\mathrm{Bal}$. \\
\hline
\end{tabular}

The as-cast K24 alloy can be directly used without heat treatment. Heat treatment of the DZ24 cast specimens (DZ-H) is given as follows: $1220^{\circ} \mathrm{C} / 4 \mathrm{~h} \mathrm{AC}+980^{\circ} \mathrm{C} / 16 \mathrm{~h}$ $\mathrm{AC}$ (AC: air cooling). Specimens for the stress-rupture test with a diameter of $5 \mathrm{~mm}$ and a gage length of $25 \mathrm{~mm}$ were machined longitudinally from the bars. Stress-rupture was carried out at $975^{\circ} \mathrm{C}$ under a stress of $196 \mathrm{MPa}$. Samples for microstructure observation were cut from the as-cast and heat-treated and fractured specimens. The samples were fabricated by the conventional method and electrochemically etched with an electrolyte consisting of $12 \mathrm{~mL} \mathrm{H}_{3} \mathrm{PO}_{4}$ $+48 \mathrm{~mL} \mathrm{H}_{2} \mathrm{SO}_{4}+40 \mathrm{~mL} \mathrm{HNO}_{3}$. The microstructure and the fracture surface after stress-rupture tests were examined by optical microscopy (OM) and scanning electron microscopy (SEM) equipped with energy-dispersive X-ray spectroscopy (EDS).

\section{Results and discussion}

\subsection{Microstructures of the as-cast alloy}

The as-cast microstructures of K24 alloy are shown in
Fig. 2. The microstructure of the as-cast samples is heavily cored (Fig. 2(a)) and composed of $\gamma, \gamma^{\prime}, \gamma / \gamma^{\prime}$ eutectics and carbides. The blocky-shaped microstructure between the dendrites is the $\gamma / \gamma^{\prime}$ eutectic liquid at the far end of the solidification process [3-4]. The volume fraction of $\gamma / \gamma^{\prime}$ eutectics is $2 \%$. The $\gamma / \gamma^{\prime}$ eutectics are known as solidification defects, which affect the ductility obviously [5-6]. The average volume fraction of $\gamma^{\prime}$ in the as-cast condition is determined by surface area measurement from the SEM micrograph, and it is found to be $70 \%$ of the matrix with the size of 0.6 to $2 \mu \mathrm{m}$. Fig. 2(b) is the SEM micrograph of the as-cast K24 emphasizing on the morphologies of $\gamma^{\prime}$ distribution. It can be seen that the average size of $\gamma^{\prime}$ in interdendritic regions is larger than that in dendrite cores (Fig. 2(b)). Fig. 2(c) shows that $\gamma^{\prime}$ particles in the interdendritic region possess irregularly aligned cubic morphology, and some of them have been split from their corners.

In DZ24 alloy, the microstructure of directionally solidified castings is shown in Fig. 3. The microstructure of as-cast samples is heavily cored (Fig. 3(a)). The microstructure of the alloy consists of cuboidal $\gamma^{\prime}$, carbides, and $\gamma^{\prime} / \gamma$
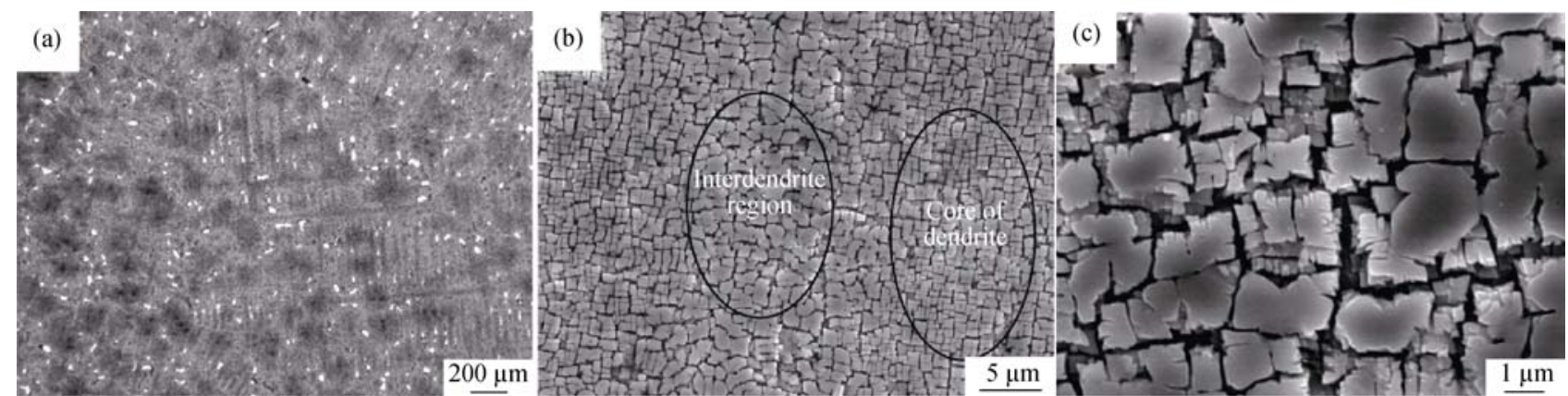

Fig. 2. Micrographs of the as-cast K24 alloy: (a) dendritic pattern; (b) morphology of $\gamma^{\prime}$ distribution; (c) morphology of $\gamma^{\prime}$ phase in the interdendritic region. 

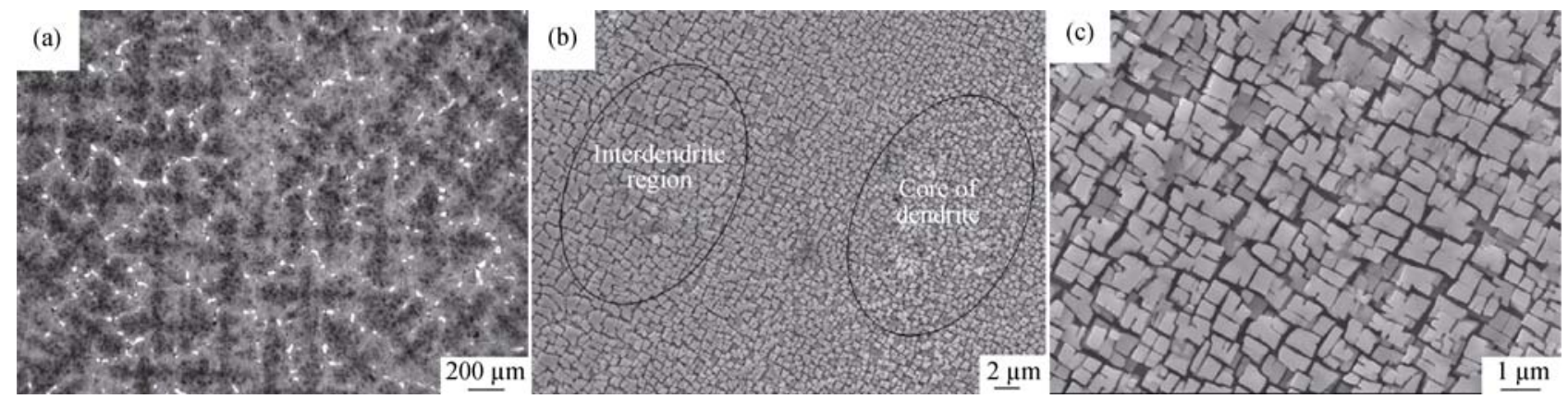

Fig. 3. Micrographs of the as-cast DZ24 alloy: (a) dendritic pattern; (b) morphology of $\gamma^{\prime}$ distribution; (c) morphology of $\gamma^{\prime}$ phase in the interdendritic region.

eutectics in the $\gamma$ matrix. A limited amount (nearly $2 \%$ ) of $\gamma^{\prime} / \gamma$ eutectics are distributed in the interdendritic area, as shown in Fig. 3(a). The average volume fraction of $\gamma^{\prime}$ phase is found to be $75 \%$ of the matrix with the average ledge size of 0.2 to $0.9 \mu \mathrm{m}$. Fig. 3(b) shows the SEM micrograph of the as-cast DZ24 emphasizing on the morphology of $\gamma^{\prime}$ distribution. The size of $\gamma^{\prime}$ phase in interdendritic regions is larger than that in dendrite cores. The morphology of $\gamma^{\prime}$ phase in the interdendritic region is shown in Fig. $3(\mathrm{c})$.

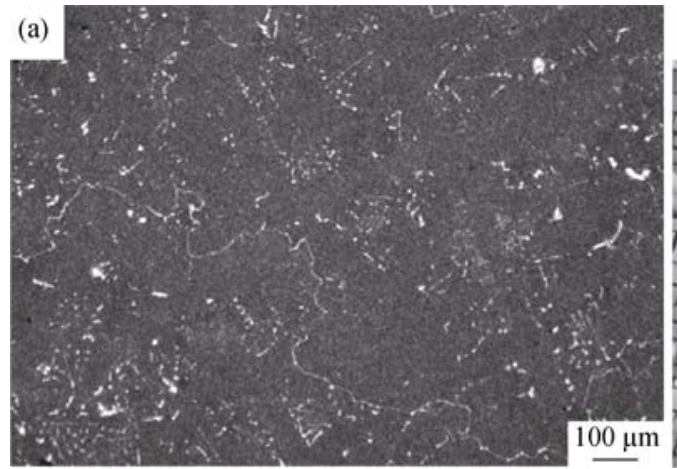

Fig. 4. OM (a) and SEM (b) morphologies of $\gamma^{\prime}$ phase in DZ24 alloy after heat treatment.

The as-cast microstructures of K24 and DZ24 alloys both have serious dendritic patterns due to the partitioning of some elements to dendrite cores and interdendritic regions. Heavy elements, such as $\mathrm{W}$ and Mo with high melting points, tend to segregate at the core of dendrites, while the interdendritic region of the as-cast microstructure is enriched in $\mathrm{Al}$ and $\mathrm{Ti}$ [7]. Due to the segregation of solute elements, the cast microstructures are different in each part of the casting. The average size of $\gamma^{\prime}$ in interdendritic regions is larger than that in dendrite cores. The microstructures of K24 and DZ24 alloys have an irregular cubic morphology. The volume fraction of $\gamma^{\prime}$ phase precipitating in DZ24 alloy is larger than that in K24 alloy, and the size of $\gamma^{\prime}$ phase precipitating in DZ24 alloy is smaller than that in K24 alloy.

To eliminate the elemental segregation and obtain uniform microstructures, homogenization treatment was per-

\subsection{Microstructures of DZ24 after heat treatment}

After heat treatment, the segregation of alloy elements is dramatically reduced by diffusion at high solution temperature. The prime $\gamma^{\prime}$ phase and $\gamma^{\prime} / \gamma$ eutectics are dissolved in $\gamma$ phase, and the dendritic structure is completely removed (Fig. 4(a)). Fine and regularly aligned cubic $\gamma^{\prime}$ phase of 0.3 to $0.5 \mu \mathrm{m}$ in size reprecipitates homogeneously during aging, as shown in Fig. 4(b). The average volume fraction of $\gamma^{\prime}$ phase in the matrix is $79 \%$.

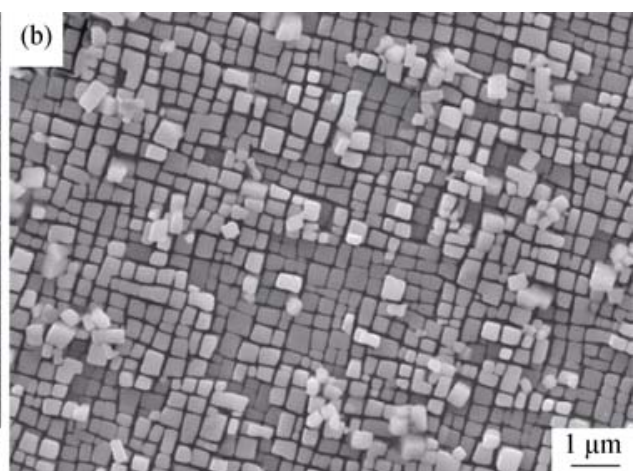

formed by high-temperature diffusion. After the treatment, coarse $\gamma^{\prime}$ and $\gamma / \gamma^{\prime}$ eutectics in the as-cast microstructure are fully dissolved into the $\gamma$ matrix and the fine and regular cubic $\gamma^{\prime}$ reprecipitates. The microstructure is much ideal and beneficial to the mechanical properties of this alloy.

\subsection{Carbides}

K24 and DZ24 superalloys comprise of blocky and script carbides in the as-cast structure (Fig. 5). EDS analyses show that these carbides are $\mathrm{MC}$ carbides, where $\mathrm{M}$ is predominantly $\mathrm{Ti}$ and $\mathrm{Nb}$, as shown in Figs. 5(c) and 5(d). The blocky-shaped MC carbides are located at grain boundaries and in interdendritic regions. The script carbides are so-called 'Chinese script' with long arms extending to the grain boundaries and primary $\gamma^{\prime}$ islands, which will promote the initiation and propagation of cracks and impair the mechanical properties [8-9]. 


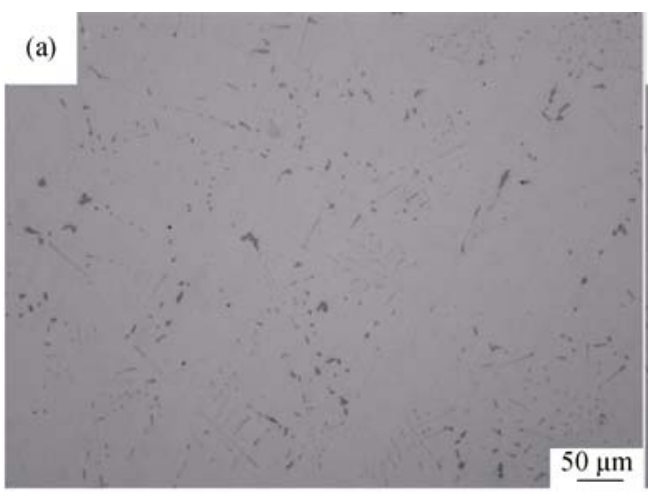

(b)
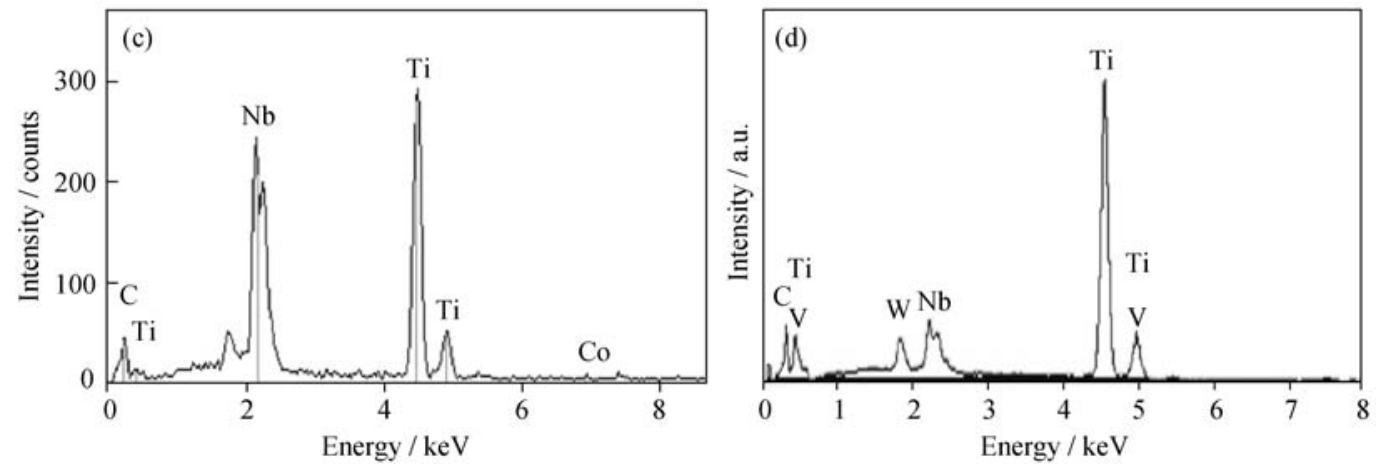

Fig. 5. Microstructures of MC in K24 (a) and DZ24 (b) alloys as well as EDS spectra of MC in K24 (c) and DZ24 (d) alloys.

After heat treatment, primary MC carbides are still present, and their compositions remain the same in DZ-H superalloy, but their shape and size are changed slightly (Fig. $6)$. The formation of $\gamma^{\prime}$ envelope around MC carbides is observed (Fig. 6(a)). The overall interfacial energy $(\sigma)$ around the carbide includes $\sigma_{\mathrm{MC} / \gamma}, \sigma_{\mathrm{MC} / \gamma^{\prime}}$ and $\sigma_{\gamma / \gamma^{\prime}}$, where $\sigma_{\mathrm{MC} / \gamma}$ is the interfacial energy between $\gamma$ and $\gamma^{\prime}$ phases, $\sigma_{\mathrm{MC} / \gamma^{\prime}}$ is the interfacial energy between $\mathrm{MC}$ and $\gamma^{\prime}$ phases, and $\sigma_{\mathrm{MC} / \gamma}$ is the interfacial energy between $\mathrm{MC}$ and $\gamma$ phases. In boron-containing alloys, boron addition induces the formation of $\gamma^{\prime}$ envelope, and carbon atoms may be replaced by boron during the formation of carbides [10]. Since the misfit of $\mathrm{MC} / \gamma$ in boron-containing carbides will increase due to the large atom size of boron, $\sigma_{\mathrm{MC} / \gamma}$ may increase. The $\sigma_{\mathrm{MC} / \gamma^{\prime}}$ may

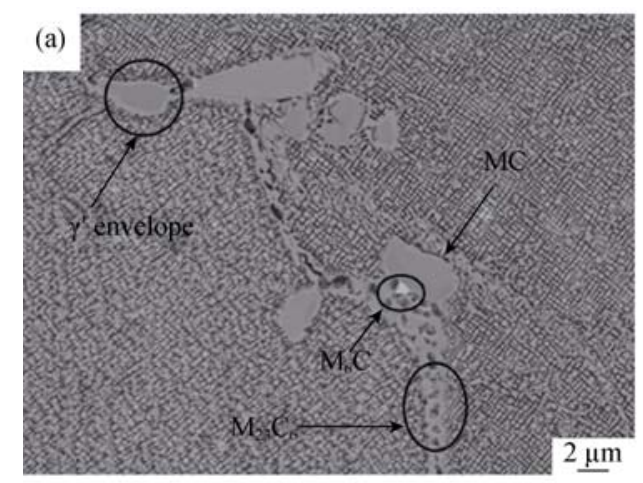

also increase as the lattice constants of $\gamma$ and $\gamma^{\prime}$ are very close at high temperature. Consequently, the only way to compensate the increase in overall interfacial energy seems to be the reduction of interfacial energy between $\gamma$ and $\gamma^{\prime}$ phases around the carbide. On the other hand, $\gamma^{\prime}$ forming elements, such as $\mathrm{Al}$ and $\mathrm{Ti}$, are rich near the primary $\mathrm{MC}$ carbides after solidification. Consequently, $\gamma^{\prime}$ envelopes form around the boron-containing carbides. In addition, the $\gamma^{\prime}$ envelope is relatively ductile, which can prevent the propagation and have a beneficial effect on the creep lifetime [10-11].

Carbide reactions during the aging at $980^{\circ} \mathrm{C}$ for $16 \mathrm{~h}$ cause the precipitation of discrete $\mathrm{M}_{23} \mathrm{C}_{6}$ and $\mathrm{M}_{6} \mathrm{C}$ grain boundary carbides:

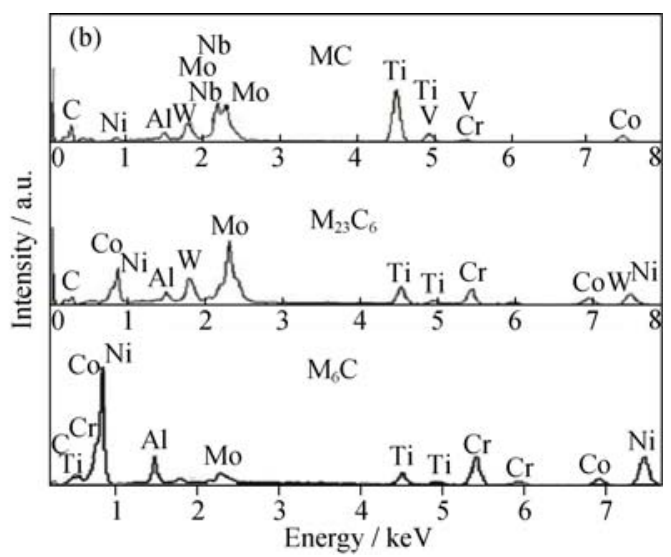

Fig. 6. Microstructure (a) and EDS spectra (b) of carbides in DZ alloy after heat treatment. 
$\mathrm{MC}+\gamma \rightarrow \mathrm{M}_{6} \mathrm{C}$ or $\mathrm{M}_{23} \mathrm{C}_{6}+\gamma^{\prime}$ [11-13].

The presence of refractory metal elements, such as $\mathrm{W}$ and Mo, leads to the precipitation of $\mathrm{M}_{6} \mathrm{C}$ carbides (Fig. 6) on the gain boundary. After aging for a long time, carbon has enough time to diffuse and react with $\mathrm{Cr}$ to form $\mathrm{M}_{23} \mathrm{C}_{6}$ carbides ( $\mathrm{M}$ rich in $\mathrm{Cr}$ ) (Fig. 6(b)). Obviously, $\mathrm{M}_{23} \mathrm{C}_{6}$ carbide precipitates at grain boundaries are the ideal morphology for inhibiting grain boundary sliding. Fine $\mathrm{M}_{6} \mathrm{C}$ carbides can effectively reduce local stress concentration and increase the resistance of shearing $\gamma^{\prime}$ phase, which are beneficial to creep properties [14-15].

\subsection{Rupture properties}

Stress-rupture tests were conducted at $975^{\circ} \mathrm{C}$ under a stress of $196 \mathrm{MPa}$. The rupture time of K24 and DZ-H alloys is 53.7 and $175.6 \mathrm{~h}$, respectively. The rupture time of DZ-H alloy is two times longer than that of K24 alloy. The microstructures of the longitudinal section after the rupture test were observed by SEM. Fig. 7 illustrates the microstructures $2 \mathrm{~cm}$ apart from the fracture surface and near the fracture surface of the ruptured specimens, respectively.

After the rupture test, the rafted $\gamma^{\prime}$ microstructure is not found in K24 alloy $2 \mathrm{~cm}$ apart from the fracture surface and near the fracture surface of the ruptured specimens. In K24 alloy, the spacing between $\gamma^{\prime}$ precipitates is wide because of the small volume of $\gamma^{\prime}$ precipitates. It is difficult for $\gamma^{\prime}$ particles to join each other; therefore, no raft $\gamma^{\prime}$ microstructure is (Figs. 7(a)-(c)). The formation of such rafts is known to occur in DZ-H alloy by the growth of precipitates perpendicular to the direction of stress followed by their coalescence (Figs. 7(d)-(f)). In the high-temperature stress-rupture test, the atoms diffuse fast, and the higher uniaxial stress provides a favorable environment for the growth along the same orientation and rafting of $\gamma^{\prime}$. The $\gamma^{\prime}$ rafts in the necked zone (near the fractured surface, Fig. 7(f)) are no longer perpendicular to the tensile load axis but inclined to it. In addition, the fine and spherical $\gamma^{\prime}$ phase precipitates have a radius of about $50 \mathrm{~nm}$ in the matrix channel during the rupture test (Fig. 8). The spherical $\gamma^{\prime}$ phase precipitates more as the distance to the fractured surface becomes smaller.
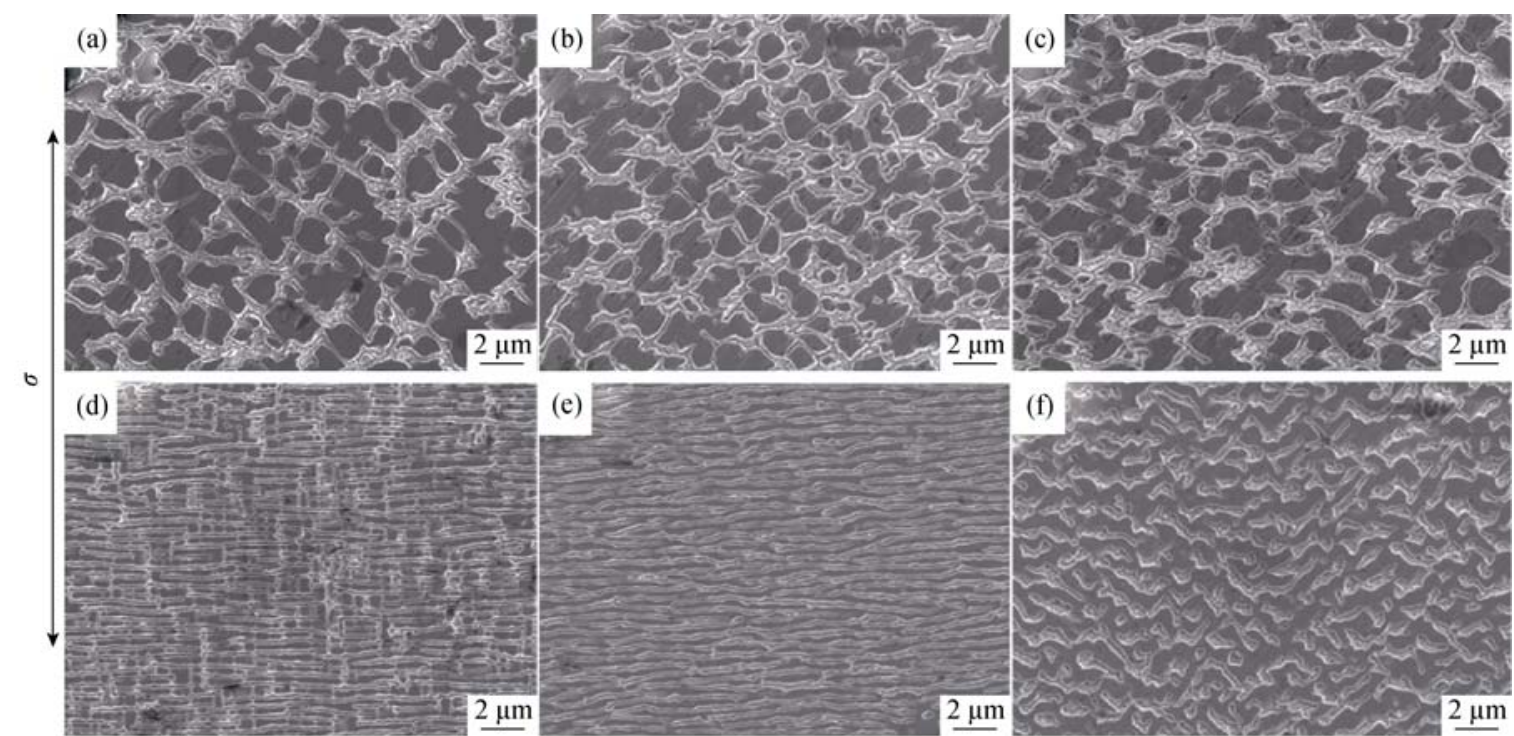

(e)

$$
2 \mathrm{~mm} \leftarrow
$$
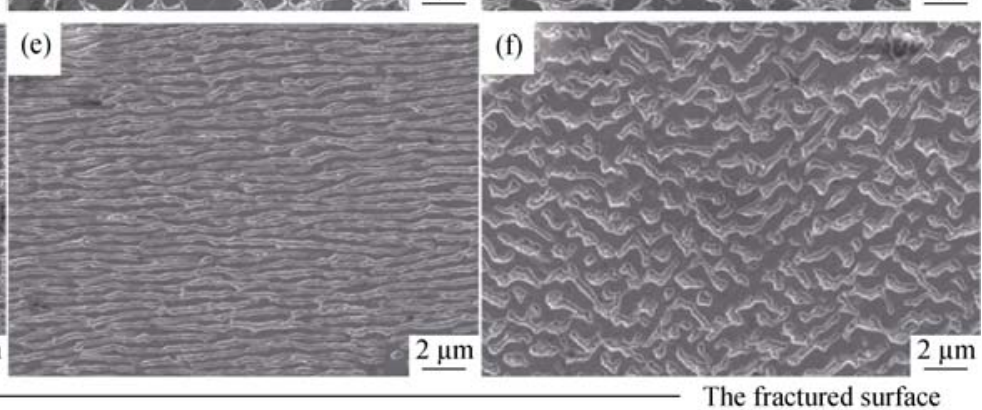

Fig. 7. SEM images of the directional coarsening of $\gamma^{\prime}$ precipitates $2 \mathbf{~ m m}$ away from the fractured surface, near the fractured surface, and at the fractured surface, respectively: (a)-(c) K24; (d)-(f) DZ-H alloy.
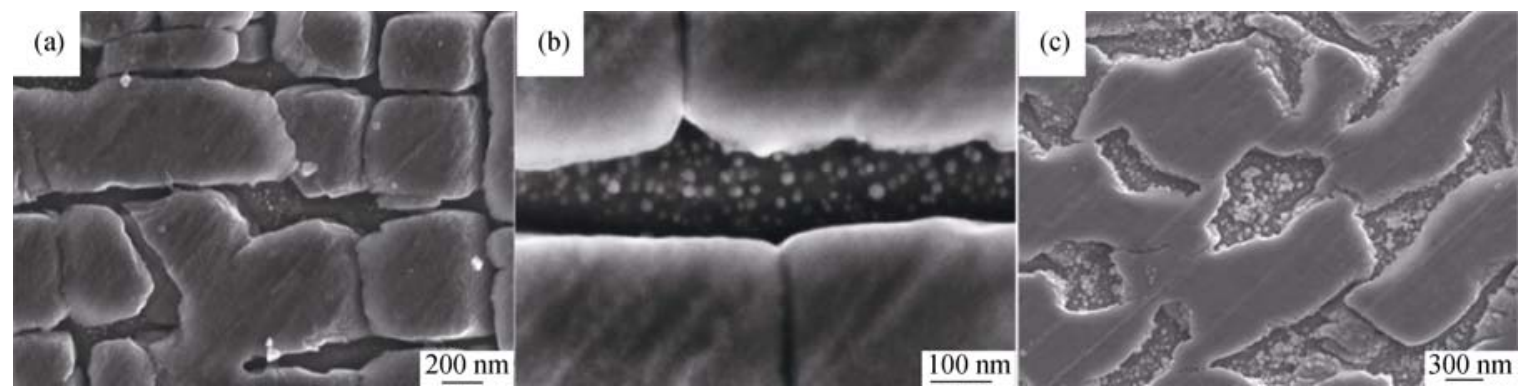

Fig. 8. SEM images of fine and spherical $\gamma^{\prime}$ precipitates at different sites in DZ-H alloy: (a) 2 mm away from the fractured surface; (b) near the fractured surface; (c) at the fractured surface. 
Directional coarsening of $\gamma^{\prime}$ phase is the result of the integrated action of thermodynamics and kinetics. During high-temperature uniaxial tensile rupture, the distance of atom diffusion and the elastic strain energy increase. The growth of $\gamma^{\prime}$ phase has high rate, and it is easy for neighboring $\gamma^{\prime}$ phase to join for the small spacing between $\gamma^{\prime}$ precipitates. On the other hand, the orientation of $\langle 100\rangle$ in the $\{100\}$ crystal plane has a lower Young's modulus [16]. The orientation of $<100>$ has large elastic stress and elastic strain energy. Therefore, initially, $\gamma^{\prime}$ phase grows in this orientation; last, $\gamma^{\prime}$ phase has the shape of rafting, which is perpendicular to the direction of stress. However, $\gamma^{\prime}$ rafts in the necked zone are no longer perpendicular to the tensile load axis but inclined to it. It is related to the variation of the deformation process. In the necked zone, the crystal lattice is rotated around the tensile load axis, thus the cross section of the specimen gradually decreases, and the multiaxial stress appears. Therefore, continuous $\gamma^{\prime}$ rafts transform into discrete $\gamma^{\prime}$ rafts. In addition, the closer to the fractured surface, the larger the rupture strain and strain energy, which makes further contributions to lattice rotation and leads to precipitates more fine and spherical $\gamma^{\prime}$ particles.

Alloys with a high volume fraction of fine and regular cubical $\gamma^{\prime}$ will provide the optimal rupture resistance. In DZ24 alloy, $\gamma^{\prime}$ precipitates are spaced as closely together as possible due to the large volume of $\gamma^{\prime}$ precipitates, and it is
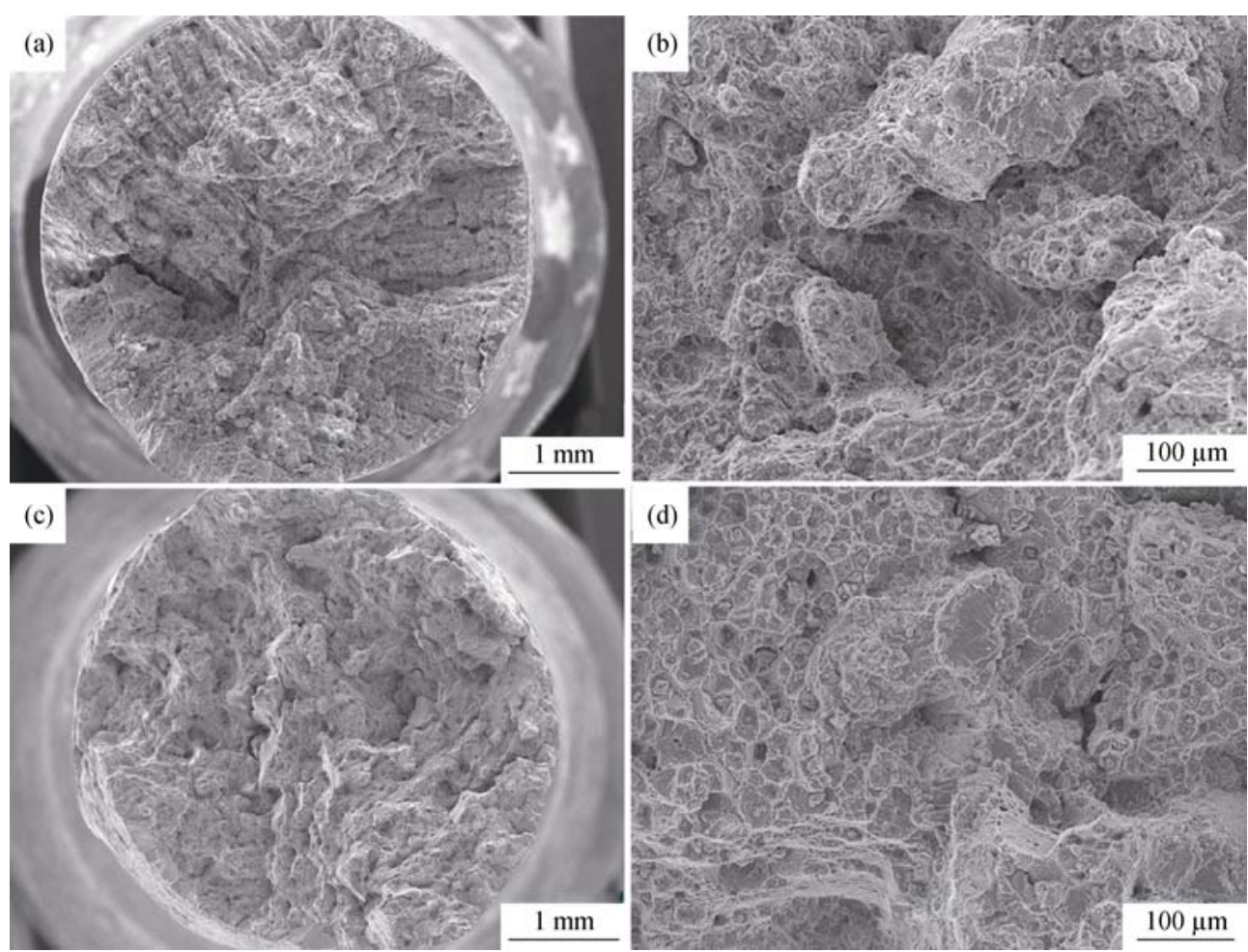

difficult to be sheared. In the process of the high-temperature rupture test, the coarsening behavior of $\gamma^{\prime}$ precipitates has significant effect on rupture properties by changing the $\gamma^{\prime}$ morphology, shape, or the matrix channel dimension. It is well known that the more even the size of cubical-shaped $\gamma^{\prime}$ precipitates, the more continuous the $\gamma^{\prime}$ rafts formed under stress ruptured conditions [17]. This structure improves the rupture resistance effectively by providing effective barriers to dislocation climb around $\gamma^{\prime}$ rafts [18-19].

\subsection{Fractographs}

The fractographs of $\mathrm{K} 24$ and DZ-H alloys after fracture during the stress rupture test at $975^{\circ} \mathrm{C}$ under a stress of 196 $\mathrm{MPa}$ are shown in Fig. 9. The fracture surface exhibits mixed intergranular and transgranular fracture features in K24 alloy. While for DZ-H alloy, transgranular fracture is observed. Figs. 9(a) and 9(b) show the fracture surfaces of K24 alloy, which indicate that cracks initiate from small cavities. The cracks start from blocky carbides or casting defects, such as shrinkage cavities and porosities. There are some dimples in the fracture surface. The fractographs of DZ-H alloy are shown in Figs. 9(c) and 9(d). There are many small cavities and large planes in Fig. 9(c). The small cavity is the site of crack initiation, and the large plane is related to $\gamma^{\prime}$ rafting. DZ-H alloy shows more dimples on the fracture surface than K24 alloy, which demonstrates that

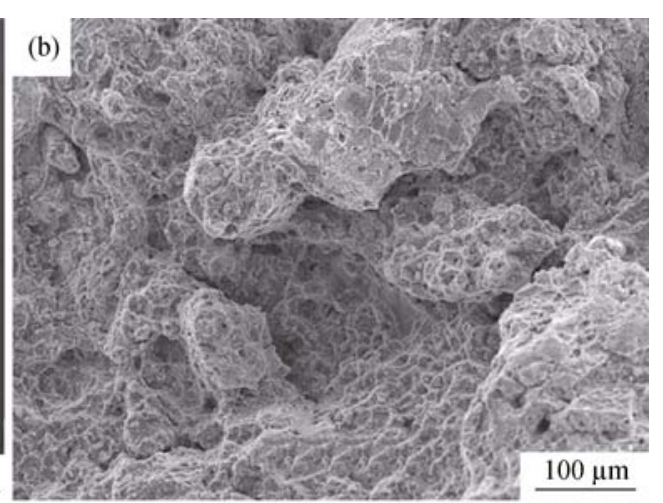

Fig. 9. Fractographs of K24 and DZ-H alloys after rupture testing: (a) macro- and (b) micro-fractographs of K24 alloy; (c) macroand (d) micro-fractographs of DZ-H alloy. 
DZ-H alloy has good ductility. The dimples start from blocky carbides or casting defects.

\section{Conclusions}

(1) The microstructures of as-cast K24 and DZ24 alloys both have serious dendritic patterns and are composed of $\gamma$, $\gamma^{\prime}$, and $\gamma / \gamma^{\prime}$ eutectics and carbides. After heat treatment, the dendritic structure was completely removed; coarse $\gamma^{\prime}$ and $\gamma / \gamma^{\prime}$ eutectics were fully dissolved into the $\gamma$ matrix; and fine and regular cubic $\gamma^{\prime}$ reprecipitated in the microstructure of DZ-H alloy.

(2) During aging, $\mathrm{M}_{23} \mathrm{C}_{6}$ carbides, $\mathrm{M}_{6} \mathrm{C}$ carbides, and $\gamma^{\prime}$ envelopes around $\mathrm{MC}$ carbides formed in DZ-H alloy, resulting from the reaction of carbides and the matrix.

(3) The rupture time of DZ-H alloy is two times longer than that of K24 alloy. In K24 alloy, the volume of $\gamma^{\prime}$ precipitates is small, the spacing between $\gamma^{\prime}$ precipitates is wide, and there is no $\gamma^{\prime}$ raft during the stress rupture test. In DZ-H alloy, $\gamma^{\prime}$ precipitates are spaced as closely together as possible due to the large volume of them, and $\gamma^{\prime}$ rafts formed under stress ruptured conditions. Alloys with a high volume fraction of fine and regular cubical $\gamma^{\prime}$ will provide the optimal rupture resistance.

\section{References}

[1] Q. Feng, T.K. Nandy, Tin. S, and T.M. Pollock, Solidification of high-refractory ruthenium-containing superalloys, Acta Mater., 51(2003), No. 1, p. 269.

[2] M.T. Jovanović, Z. Mišković, and B. Lukić, Microstructure and stress-rupture life of polycrystal, directionally solidified, and single crystal castings of nickel-based IN 939 superalloy, Mater. Charact., 40(1998), No. 4-5, p. 261.

[3] Y.Z. Zhou and A. Volek, Effect of dendrite arm spacing on castability of a directionally solidified nickel alloy, Scripta Mater., 56(2007), No. 6, p. 537.

[4] Y.Z. Zhou and A. Volek, Effect of grain boundary fraction on castability of a directionally solidified nickel alloy, Scripta Mater., 54(2006), No. 12, p. 2169.

[5] L.Y. Sheng, L.J. Wang, T.F. Xi, Y.F Zheng, and H.Q. Ye, Microstructure, precipitates and compressive properties of various holmium doped $\mathrm{NiAl} / \mathrm{Cr}(\mathrm{Mo}, \mathrm{Hf})$ eutectic alloys, $M a$ ter. Des., 32(2011), No. 10, p. 4810.

[6] L.R. Liu, T. Jin, N.R. Zhao, Z.H. Wang, X.F. Sun, H.R. Guan, and Z.Q. Hu, Effect of carbon addition on the creep properties in a Ni-based single crystal superalloy, Mater. Sci. Eng. A, 385(2004), No. 1-2, p. 105.

[7] G.E. Fuchs, Solution heat treatment response of a third generation single crystal Ni-base superalloy, Mater. Sci. Eng. A, 300(2001), No. 1-2, p. 52.

[8] W.R. Sun, J.H. Lee, S.M. Seo, S.J. Choe, and Z.Q. Hu, The eutectic characteristic of MC-type carbide precipitation in a DS nickel-base superalloy, Mater. Sci. Eng. A, 271(1999), No. 1-2, p. 143.

[9] J. Chen, J.H. Lee, C.Y. Jo, S.J. Choe, and Y.T. Lee, MC carbide formation in directionally solidified MAR-M247 LC superalloy, Mater. Sci. Eng. A, 247(1998), No. 1-2, p. 113.

[10] B.C. Yan, J. Zhang, and L.H. Lou, Effect of boron additions on the microstructure and transverse properties of a directionally solidified superalloy, Mater. Sci. Eng. A, 474(2008), No. 1-2, p. 39.

[11] C.T. Sims, N.S. Stoloff, and W.C. Hagel, Superalloys II, Wiley-Interscience, New York, 1987, p. 115.

[12] T.J. Garosshen and G.P. McCarthy, Low temperature carbide precipitation in a nickel base superalloy, Metall. Trans. A, 16(1985), No. 7, p. 1213

[13] H.S. Liu, L. Zhang, X.B. He, X.H. Qu, H.M. Zhu, and G.Q. Zhang, Effect of oxygen content and heat treatment on carbide precipitation behavior in PM Ni-base superalloys, Int. J. Miner. Metall. Mater., 19(2012), No. 9, p. 827.

[14] A.K. Jena and M.C. Chaturvedi, The role of alloying elements in the design of nickel-base superalloys, J. Mater. Sci, 19(1984), No. 10, p. 3121.

[15] L.Z. He, Q. Zheng, X.F. Sun, H.R. Guan, Z.Q. Hu, A.K. Tieu, C. Lu, and H.T. Zhu, Effect of heat treatment on microstructures and tensile properties of Ni-base superalloy M963, $M a$ ter. Sci. Eng. A, 398(2005), p. 128.

[16] P.C. Xia, J.J. Yu, X.F. Sun, H.R. Guan, and Z.Q. Hu, The influence of thermal exposure on the microstructure and stress rupture property of DZ951 nickel-base alloy, J. Alloys Compd., 443(2007), No. 1-2, p. 125.

[17] J.J. Yu, X.F. Sun, N.R. Zhao, T. Jin, H.R. Guan, and Z.Q. Hu, Effect of heat treatment on microstructure and stress rupture life of DD32 single crystal Ni-base superalloy, Mater. Sci. Eng. A, 460-461(2007), p. 420.

[18] T. Hino, T. Kobayashi, Y. Koizumi, H. Harada, and T. Yamagata, Development of a new single crystal superalloy for industrial gas turbines, [in] T.M. Pollock, R.D. Kissinger, R.R. Bowman, K.A. Green, M. McLean, S. Olson, and J.J. Schirm, eds. Superalloys 2000, TMS, Warrendale, 2000, p. 729.

[19] Z.X. Shi, J.R. Li, and S.Z. Liu, Effects of Ru on the microstructure and phase stability of a single crystal superalloy, Int. J. Miner. Metall. Mater., 19(2012), No. 11, p. 1004. 